\title{
Possible association between haemostasis dysfunction and early onset of microvascular complications in patients with type 1 diabetes
}

Możliwy związek między zaburzeniem hemostazy a wczesnym początkiem powikłań mikronaczyniowych u pacjentów z cukrzycą typu 1

\author{
Jarmila Vojtková, Katarína Motyková, Peter Bánovčin
}

Department of Pediatrics, Comenius University in Bratislava, Jessenius Faculty of Medicine in Martin, Slovak Republic

\begin{abstract}
Chronic hyperglycaemia, the effect of which is enhanced with diabetes duration and poor compensation, has a great impact on the complex aetiopathogenesis of microvascular diabetic complications. However, other factors are particularly likely in young patients with early onset of chronic complications. One of the possible risk factors is procoagulant condition, which can lead to small vessel microthromboses, endothelial damage, and ultimately specific organ manifestations. While these changes are well described in a group of adult patients with type 2 diabetes, similar information is less in the population of children and adults with type 1 diabetes (T1D). Changes in haemostasis may be associated with hyperglycaemia and subclinical inflammation or specific gene polymorphisms. Alternatively, they can occur due to coincidence with inherited thrombophilic disorders or sticky platelet syndrome. Finally, T1D is an autoimmune disease that can be associated with other autoimmune conditions, e.g. lupus anticoagulant. From the clinical point of view, mainly cases with early onset of chronic diabetic complications that cannot be explained by long duration or insufficient compensation of diabetes might be suspicious from the procoagulant changes and their screening might be discussed.
\end{abstract}

Key words:

antiphospholipid antibodies, type 1 diabetes, microvascular complications, haemostasis dysfunction, inherited thrombophilic disorders. 


\section{Introduction}

Diabetes mellitus is a chronic metabolic disease with increasing incidence worldwide, which can reduce the quality of life through chronic diabetic complications. Macrovascular complications are the main cause of morbidity and mortality among diabetic patients. Microvascular complications may occur early after diabetes onset and, by affecting the smallest vessels, can lead to dysfunction of almost all organ systems. The most important risk factor in their complex aetiology is chronic hyperglycaemia, the impact of which is enhanced by poor compensation and long duration of diabetes. Hyperglycaemia stimulates many pathophysiological processes interacting with each other - non-enzymatic protein glycation, polyol pathway, oxidative stress, hexosamine pathway, pro-inflammatory cytokines, nuclear factor kappa B or protein kinase C. In addition, glycaemic variability, dyslipidaemia, hypertension, and inflammation play a role [1-5]. In clinical practice, however, there are also individuals who suffer from chronic complications shortly after diabetes onset with relatively satisfactory compensation. Although such complications are often automatically labelled "diabetic", they may actually be related to other factors, including genetic predisposition, epigenetic changes, or various pathological conditions. Because vascular abnormality is a common denominator of microvascular complications, a possible risk factor is dysfunction of haemostasis leading to impaired vascular flow.

One of the well-known secondary causes of haemostasis dysfunction towards hypercoagulation is type 2 diabetes (T2D) that has been found to be associated with endothelial damage, platelet hyperreactivity, increased concentration of coagulation factors, decreased anticoagulant factors, and alteration in fibrinolysis [6-8]. Changes in coagulation are, however, described less often in individuals with type 1 diabetes (T1D), especially in childhood. These changes may be associated with hyperglycaemia, similarly to T2D. Another possibility is the coincidence of T1D and congenital thrombophilic conditions or sticky platelet syndrome, or a genetic predisposition (milder changes in coagulation factors) to haemostasis dysfunction. Last but not least, T1D is an autoimmune disease that may be associated with other autoimmune conditions, including lupus anticoagulant.

\section{Haemostasis dysfunction and type 2 diabetes mellitus}

Haemostasis changes associated with hyperglycaemia have been extensively described in many publications in T2D patients: endothelium dysfunction, platelet hyperreactivity, increased concentration of coagulation factors (fibrinogen, Factor V, VII, VIII, IX, X, XI, XII, von Willebrand factor), decreased concentration of anticoagulant factors (antithrombin III, protein $\mathrm{C}$ ), and alteration of fibrinolysis (increased concentration of plasminogen activator inhibitor 1, PAl-1; decreased concentration of tissue plasminogen activator, tPA) [7, 8]. Hae- mostasis dysfunction in diabetic patients is likely to contribute to cardiovascular diseases [9]; however, its association with microvascular complications is under debate. The predicted pathophysiological processes include chronic hyperglycaemia, subclinical inflammation, insulin resistance, and dyslipidaemia, which interact with each other and through non-enzymatic protein glycation (advanced glycation end-products - AGEs), oxidative stress, and activation of pro-inflammatory cytokines may modify platelets, coagulation, and fibrinolytic factors $[1,8]$.

In detail, in the condition of hyperglycaemia, platelets are more prone to aggregation through non-enzymatic glycation of platelet membrane proteins with consequently increased expression of certain glycoproteins (Ib-IX, IIb/IIla) and receptors necessary for platelet function. Hyperglycaemia per se triggers mobilisation of $\mathrm{Ca}^{2+}$ from intracellular stores and increases intracellular concentration of $\mathrm{Ca}^{2+}$. Enhanced consumption of platelets may lead to accelerated thrombopoiesis of more reactive young platelets [10]. Glycation of platelet membrane proteins leads to decreased membrane fluidity and is associated with platelet hyperreactivity to thrombin. Diabetes is related to overexpression of inflammatory cytokines (TNF- $\alpha$ and IL-6), which may stimulate endothelial expression of Factor VIII and von Willebrand factor (VWF). Overproduction of reactive oxygen species may modify functional properties of VWF. Moreover, elevated concentration of VWF, vascular cell adhesion molecule, endothelin-1, and E-selectin on one hand, and decreased production of nitric oxide (NO) and prostacyclin as vasodilators on the other hand, contribute to endothelial cell damage and prothrombotic state [9]. Increased concentration of tissue factor in diabetic patients may be related to its release by adipocytes and macrophages in the condition of hyperglycaemia and hyperinsulinism. Production of tissue factor is enhanced by nuclear factor kappa $B$, which is activated by reactive oxygen species and advanced glycation end products. Similarly, increased level of fibrinogen can be related to inflammatory cytokines (produced by adipocytes and macrophages), which induce its production in the liver; also to oxidative stress that can modify its functional properties. In terms of impaired fibrinolysis, increased concentration of PAl-1 may be due to its enhanced liver synthesis influenced by low-grade inflammatory condition and hyperinsulinaemia. Moreover, cytokines, mediators (tumour growth factor $\beta$ ), and reactive oxygen species are able to induce the synthesis and release of PAl-1 from adipocytes and endothelial cells [10].

\section{Haemostasis dysfunction and type 1 diabetes mellitus}

Chronic hyperglycaemia and subclinical inflammation is a common factor in type 2 as well as type 1 diabetes [11], and it may lead to similar pathophysiological changes.

Endothelium alteration in $\mathrm{T} 1 \mathrm{D}$ is related to numerous pathophysiological mechanisms: oxidative stress and AGEs, alteration in the expression or structure of nitric oxide synthase 
(NOS), reduction of substrate for NOS (L-arginine), NO destruction, and reduction of endothelial progenitor cells, which are able to activate endothelial reparative processes [12]. Preadolescent T1D children have higher high-sensitivity C-reactive protein as a marker of inflammation and attenuated measurements of flow-mediated dilatation of the brachial artery as a marker of endothelial dysfunction [13]. In T1D patients with impaired renal function, plasma levels of AGEs were significantly associated with markers of endothelial dysfunction (soluble vascular adhesion molecule-1, vWF, and soluble thrombomodulin) independently of renal function [14]. In T1D children, lower glutathione peroxidase and higher nitrate/nitrite and lipid hydroperoxide levels are found compared to healthy children. This decreased antioxidative protection is parallel with endothelial / platelet activation - increased P-selectin and tetranectin levels that are more pronounced with diabetes progression [15]. The mean levels of plateletderived microparticles and circulating endothelial cells were significantly higher in T1D children compared to healthy controls and were closely affected by the poor glycaemic control and dyslipidaemia [16]. Moreover, severe hypoglycaemia is also associated with marked reduction in stem cells and endothelial progenitor cells [17]. Reducing glucose variability with continuous subcutaneous insulin infusion increases the level of circulating endothelial progenitor cells [18].

Platelets in diabetic patients show dysregulated signalling pathways, leading to platelet hyperactivation and increased risk of microcapillary embolisation [19]. Children with newly diagnosed as well as with established T1D have significantly elevated mean platelet volume and platelet distribution width compared to healthy subjects, which may be related to oxidative stress within T1D [20]. Similarly, children with T1D have altered morphological platelet parameters (higher mean platelet volume, platelet distribution width, and platelet large-cell ratio) and duration of diabetes with poor glycaemic control, which seem to be significant risk factors [21]. Adult T1D subjects with wellcontrolled diabetes have enhanced in vivo platelet activation (elevated biosynthesis of thromboxane A2) and oxidative stress (higher biosynthesis of F2-isoprostane) [22]. Children with T1D have significantly more frequent morphological changes in platelet hyperreactivity compared to healthy controls, with a higher platelet count associated with poorer metabolic control of diabetes [23]. Even children with newly diagnosed T1D have structural and functional modification of platelet membrane and alterations of nitric oxide metabolism (reduced $\mathrm{Na}^{+} \mathrm{K}+\mathrm{ATP}$-ase activity and nitric oxide levels and increased production of peroxynitrite) compared to controls. These changes seem to be due to diabetes per se and not to chronic hyperglycaemia, insulin therapy, or ageing [24]. According to Swedish authors, postprandial platelet activation via the thromboxane pathway is related to postprandial hyperinsulinaemia not to postprandial hyperglycaemia in T1D patients [25].

Diabetes mellitus is associated with hypercoagulable state. Turkish authors reported shorter clotting time and increased clot firmness (using rotational thromboelastometry) in children with T1D, suggesting hypercoagulation status [26]. Youths with T1D have impaired prothrombotic state. PAl-1 antigen and vWF-antigen positively correlate with impaired lipid profile and VWF-antigen, as well as with suboptimal glycaemic control [27]. PAI-1 levels are significantly increased in T1D children compared to healthy subjects and positively correlate with random blood glucose, $\mathrm{HbA1c}$, lipids, and carotid intima media thickness [28]. Basal tissue factor procoagulant activity and plasma coagulation factor VIla are higher in T1D patients compared to healthy controls; however, the regulating mechanisms seem to be different in patients with T1D and T2D [29]. On the other hand, according to a study by Austrian authors, children with T1D have only minimal changes in thrombin formation, which do not correlate with metabolic control or the duration of diabetes [30]

The association between haemostasis dysregulation and microvascular complications in T1D patients is highly likely. Platelet-lymphocyte aggregation is significantly higher in patients with T1D with nephropathy compared to T1D patients without nephropathy [31]. Thrombin-induced platelet P-selection expression is enhanced, and soluble P-selection and SCD40L concentration is increased in T1D patients with microangiopathy compared to control subjects and patients without microangiopathy. C-reactive protein and E-selection is increased in T1D patients with microangiopathy compared to controls, and von Willebrand factor antigen does not differ between the groups [32]. Increased VWF, ADAMTS13 (metalloproteinase), and D-dimer levels are associated with renal dysfunction in T1D patients [33]. The same research group has found that ADAMTS13 activity, D-dimers, and cystatin C are associated with retinopathy in T1D patients [34]. According to the DCCT/EDIC study, plasma markers of inflammation (soluble tumour necrosis factor receptors-1 and -2), endothelial dysfunction (E-selectin) and clotting/fibrinolysis (fibrinogen and PAI-1) are associated with progression to kidney dysfunction in T1D patients [35]. In T1D patients with diabetic nephropathy, markers of endothelial dysfunction (sVCAM-1, PAI-1, and SICAM-1) have been associated with the rate of decline in glomerular filtration rate [36]. PAI-1 levels are significantly increased in T1D children with micro-vascular complications compared to those without [28]. D-dimer, as a marker of coagulation cascade and fibrinolysis activation, is significantly elevated among T1D children with retinopathy, neuropathy, and nephropathy compared to non-complicated patients, and it positively correlates with blood pressure and albumin creatinine ratio [37]. Moreover, an increase of VWF concentration precedes microalbuminuria in T1D children, so it could be used to identify patients at risk of developing incipient nephropathy [38].

\section{Inherited thrombophilic disorders}

The prevalence of inherited thrombophilic disorders (ITD) is about 40 per 100,000 inhabitants. The frequency of some mutations in the population is relatively high, e.g. Factor $\mathrm{V}$ Leiden mutation is reported to be about 3-7\% (Table I), with the occurrence of mutations several times higher in the 
Table I. Frequency of selected inherited thrombophilic disorders (according to 39)

\begin{tabular}{llll}
\hline $\begin{array}{l}\text { Inherited thrombophilic disorders } \\
\text { F. V Leiden mutation }\end{array}$ & Frequency in common population & Frequency in patients with VTE & Relative risk \\
\hline $\begin{array}{l}\text { (G1691A) } \\
\text { Prothrombin mutation }\end{array}$ & $3-15 \%$ & $15-30 \%$ & 5 \\
(G20210A) & $1-2 \%$ & $4-7 \%$ & $2-3$ \\
\hline Deficiency of protein C & $0.2-0.4 \%$ & $3-5 \%$ & 10 \\
\hline Deficiency of protein S & $0.3-1.3 \%$ & $1.5 \%$ & 10 \\
\hline $\begin{array}{l}\text { Hyperhomocysteinaemia } \\
(>15 \mu \text { mol/I) }\end{array}$ & $5 \%$ & $10 \%$ & 2.5 \\
\hline Deficiency of antithrombin III & $0.1-0.2 \%$ & $1-3 \%$ & $15-20$ \\
\hline Hyperactivity of f. VIII & $5-11 \%$ & $25 \%$ & 5 \\
\hline
\end{tabular}

VTE - venous thromboembolism

population of patients with venous thromboembolism [39]. For the development of thrombosis, not only the mutation itself is sufficient, but also the presence of other risk factors (smoking, hormonal therapy, immobility, other procoagulant risk factors) is usually necessary. Currently, patients with venous thrombosis and pulmonary embolism less than 45 years old, after arterial thrombosis less than 35 years old, with recurrent thrombosis, atypical thrombosis, inadequate response to anticoagulant therapy, or with habitual abortion are indicated for ITD screening. Treatment is anticoagulant and/or antiplatelet, depending on the type of disease confirmed.

Due to the relatively high incidence of these conditions in the general population, it is also likely to occur in patients with diabetes. We hypothesise that coincidence of T1D with inherited thrombophilic disorders might contribute to the early onset of chronic diabetic complications despite a short duration of T1D and satisfactory metabolic compensation. Higher frequency of the heterozygous form of Leiden mutation has been found in adult diabetic patients with unsuccessful outcome of percutaneous transluminal angioplasty [40]. Regarding T1D, individual case reports about complications associated with inherited thrombophilia have been published. American authors described a case report of a 12-year-old girl with massive arterial thrombosis with a Factor $V$ Leiden mutation and a twoyear history of under-compensated T1D [41]. Spanish authors published a case of a 15-year-old male with poorly controlled T1D with neurological manifestations of cerebral hypertension, where cerebral venous sinus thrombosis has been suggested. Factor V Leiden G1691A gene mutation was diagnosed, which probably contributed to cerebral venous thrombosis in the interaction with bad metabolic control and viral infection [42]. The condition of diabetic ketoacidosis seems to represent an additional risk factor for thrombus formation [43].

On the other hand, a study of Turkish authors did not find a significant difference in mean normalised activated protein $C$ sensitivity ratio values and prevalence of heterozygous factor $V$ Leiden mutation in T1D patients and healthy controls. Moreover, these parameters were not associated with metabolic control parameters, lipids, and diabetic complications in T1D patients with mean age of 27.9 years [44]. Paradoxically, factor $\mathrm{V}$ Leiden mutation may have a protective effect in diabetic nephropathy, which can be explained by low chronic coagulation activation that may ameliorate glucose-induced podocyte apoptosis [45].

Sticky platelet syndrome is platelet hyperaggregability after activation by adenosine diphosphate and/or epinephrine. In addition to the autosomal dominant type of inheritance, a polygenic type of inheritance is also possible. Although the prevalence in the general population is unknown, a prevalence of up to $17-28 \%$ is reported in the population of patients with venous thromboembolism [46]. Patients with this syndrome have more frequent arterial thrombosis and benefit from antiplatelet therapy. Unrecognised sticky platelet syndrome may complicate many conditions such as kidney transplantation [47] or angioplasty surgery [48]. In addition to many other factors (e.g. dyslipidaemia, hypertension, associated chronic inflammatory diseases, trauma, medications, vitamin deficiencies), also unrecognised sticky platelet syndrome may participate in the complex pathogenesis of diabetic microvascular complications. Again, the question is whether T1D patients with early onset of chronic complications should undergo screening for the presence of sticky platelet syndrome. 


\section{Genetic predisposition}

In addition to the mentioned mutations leading to a thrombophilic state, there are several dozen described gene polymorphisms encoding proteins involved in haemostasis (Table II). These minor gene variants may result in functional modification in terms of changes in plasma concentration or properties of the proteins [49]. Although these gene polymorphisms themselves do not lead to thrombotic complications, they may, in conjunction with other risk factors (such as hyperglycaemia), represent a multifactorial predisposition to thrombus formation and vascular abnormality.

Studies focusing on an association between these gene variants and diabetic complications have been provided mainly in adult T2D populations. A meta-analysis of nine studies found that diabetic retinopathy is associated with platelet glycoprotein receptor $\alpha 2 \beta 1$ integrin (ITGA2) and glycoprotein IIla (ITGB3) gene polymorphisms [50]. ITGA2 gene polymorphisms are associated also with chronic kidney disease in T2D patients [51]. According to a meta-analysis in the Chinese population, 4G allele (PAl-1 gene variant) might be a risk factor for diabetic nephropathy [52]. The association between PAI-1 gene polymorphisms and diabetic retinopathy is controversial. A meta-analysis of nine studies suggested the increased risk among the Caucasian population and higher susceptibility in patients with longer duration of diabetes [53]. Another study, however, did not provide strong evidence that PAl-1 gene polymorphisms are associated with the risk of diabetic retinopathy during the course of T2D [54].

\section{Antiphospholipid antibodies}

Type 1 diabetes is an autoimmune disease of the pancreatic $\beta$ cells the aetiology of which includes genetic predisposition along with environmental factors. The presence of T1D in a particular patient is the result of dysregulation of the immune system and impaired tolerance of self-antigens; therefore, it is not surprising that these patients may also have other associated autoimmune diseases, including antiphospholipid syndrome (APS). The antiphospholipid syndrome is a form of thrombotic microangiopathy, characterised by the presence of antiphospholipid antibodies (anticardiolipin, against $\beta 2$ glycoprotein 1 or lupus anticoagulant) with a complex effect on haemostasis (Table III). The antiphospholipid syndrome is associated with higher risk of cardiovascular diseases [55], and typical symptoms include recurrent miscarriages, arterial or venous thrombi, and thrombocytopaenia, but also very

Table II. Selected gene polymorphisms predisposing to procoagulant condition (modified according to 49)

\begin{tabular}{|c|c|c|c|}
\hline Part of haemostasis & Gene (chromosome) & Candidate gene variant & Function consequence \\
\hline $\begin{array}{l}\text { Platelets } \\
\text { GP la-lla ( } \alpha 2 \text { subunit) }\end{array}$ & ITGA2 (5q23-31) & C807T & $\begin{array}{l}\text { Determinant of integrin dense and activity } \\
\text { of collagen receptors }\end{array}$ \\
\hline \multicolumn{4}{|l|}{ Procoagulant factors } \\
\hline Fibrinogen & FGA (4q31) & Thr-312Ala & Increased stability of thrombus \\
\hline Factor II & $F 2(11 p 11-q 12)$ & G20210A & Determinant of plasmatic concentration \\
\hline Factor V & F5 (1q23) & Arg-506Gln & Activated protein $\mathrm{C}$ resistance \\
\hline Factor VII & F7 (13q34) & Arg-353Gln & Determinant of plasmatic concentration \\
\hline Tissue factor & F3 (1p22-21) & 1208D/l promoter & Determinant of plasmatic concentration \\
\hline \multicolumn{4}{|c|}{ Anticoagulant proteins } \\
\hline Anti-thrombin III & AT3 (1q23-25) & \multirow{3}{*}{$\begin{array}{l}>130 \text { loss-of-function } \\
\text { mutations }\end{array}$} & Deficiency of antithrombin \\
\hline Protein $\mathrm{C}$ & PC (2q13-14) & & Deficiency of protein C \\
\hline Protein S & PROS1 (3p11.1-2) & & Deficiency of protein S \\
\hline Thrombomodulin & THBD (20p11.2) & G-33A & Determinant of plasmatic concentration \\
\hline \multicolumn{4}{|l|}{ Fibrinolytic proteins } \\
\hline PAl-1 & PLANH1 (7q22.1-22.3) & $-6754 G / 5 G(D / l)$ & Determinant of plasmatic concentration \\
\hline
\end{tabular}


Table III. The impact of antiphospholipid antibodies on haemostasis

\begin{tabular}{ll}
\hline & Impact of antiphospholipid antibodies \\
\hline Platelets & Activation of adhesion and aggregation \\
\hline Endothelial & $\begin{array}{l}\text { Increased concentration of tissue factor, } \\
\text { adls }\end{array}$ \\
& $\begin{array}{l}\text { cytokines, decreased concentration of } \\
\text { prostacyclin }\end{array}$ \\
\hline Coagulation & $\begin{array}{l}\text { Inhibition of protein C, protein S and } \\
\text { and fibrinolysis }\end{array}$ \\
& of antithrombin III, inhibition of fibrinolysis \\
\hline Placenta & $\begin{array}{l}\text { Increased apoptosis, decreased growth } \\
\text { of trophoblasts }\end{array}$ \\
\hline
\end{tabular}

diverse organ manifestations, e.g. migraine, epilepsy, neuropathy, vaso-occlusive retinopathy, nephropathy, vasculitis, or adrenal insufficiency [56]. The antiphospholipid syndrome is often associated with systemic lupus erythematosus but may also accompany other autoimmune diseases. The presence of antiphospholipid antibodies in diabetes, however, may also be related to glucose toxicity, which may induce oxidative stress and lipid peroxidation of phospholipids in the membranes.

In patients with T1D, the incidence of antiphospholipid antibodies varies according to the population, the presence of diabetes complications, the detection method, and the antibody type. Positivity of cardiolipin antibodies in the diabetic population is reported about 6.9-9.4\% [57-60], and up to $24 \%$ in newly diagnosed T1D [61]. The presence of antibodies may differ in the course of diabetes and is significantly more common in the first six months after onset of T1D diagnosis (54.5\%), which may reflect an abnormal immunological response in the early stage of T1D with increased production of various autoantibodies [61]. The prevalence of cardiolipin antibodies in T1D children (mean age 12.9 years, mean diabetes duration 3.6 years) [59] and also in T1D adults (mean age 29.1 years,

\section{References}

1. Domingueti CP, Dusse LM, Carvalho Md, et al. Diabetes mellitus: The linkage between oxidative stress, inflammation, hypercoagulability and vascular complications. J Diabetes Complications 2016; 30: 738-745. doi: 10.1016/j.jdiacomp.2015.12.018

2. Prázný M, Škrha J, Šoupal J, Škrha J Jr. Glycemic variability and microvascular complications of diabetes. Cas Lek Cesk 2017; 156: 308-313. mean diabetes duration 9.8 years) [57] is comparable with that seen in healthy subjects.

Antiphospholipid antibodies seem to be associated with macrovascular complications of diabetic patients [58], and data about the association with microvascular complications are inconsistent. According to a Serbian study, anticardiolipin antibodies positively correlated with renal impairment parameters in T2D patients [62]. Lupus anticoagulant positivity is more common in patients with diabetic retinopathy [Giusti, 63, 64]. A French study showed that phospholipid-binding antibodies are significantly more frequent in diabetes patients with nephropathy but not with retinopathy compared to uncomplicated diabetes [60].

\section{Conclusions}

The aetiopathogenesis of diabetic microvascular complications is very complex and cannot be limited only to chronic hyperglycaemia within long diabetes duration and insufficient metabolic control. Other factors are particularly likely in young patients with early onset of chronic complications. One of the possible risk factors is procoagulant condition, which can lead to small vessel microthromboses, endothelial damage, and ultimately specific organ manifestations. However, the aetiology of indicated association between T1D and haemostasis dysfunction remains unclear. Changes in haemostasis may be associated with hyperglycaemia and subclinical inflammation (as in T2D patients), lupus anticoagulant, or specific gene polymorphisms, or they can occur due to coincidence with inherited thrombophilic disorders. In view of the high prevalence in the general population, the identification of inherited thrombophilic disorders is of particular interest because it is a relatively easily treatable group of diseases (anticoagulant, antiplatelet therapy). From the clinical point of view, mainly cases of early onset of chronic diabetic complications, which cannot be explained by common risk factors (such as long diabetes duration, insufficient compensation, hyperlipidaemia, hypertension, or others), might be suspicious from the procoagulant changes. Further studies are appropriate to confirm the suitability and cost/ benefit of possible screening of haemostasis dysregulation.

The work was supported by grant VEGA 1/0310/18.
3. Dedinská I, Palkoci B, Miklušica J, et al. Metabolic syndrome and new onset diabetes after kidney transplantation. Diabetes Metab Syndr 2017; 11: 211-214. doi: 10.1089/dia.2013.0205

4. Pršo M, Brndiarová M, Králová T, Suroviaková S. Zmeny hodnôt hepatorenálneho indexu v jednotlivých obdobiach detského veku. Pediatria (Bratisl) 2019; 14: 5-8.

5. Brndiarová M, Antonyová M, Szokeová A. Various forms of chronic kidney disease - mineral and bone disorder in pediatric patients in predialysis and dialysis care. Aktuality v Nefrologii 2017; 23: 55-59. 
6. Rollini F, Franchi F, Muñiz-Lozano A, Angiolillo DJ. Platelet function profiles in patients with diabetes mellitus. J Cardiovasc Transl Res. 2013; 6: 329-345. doi: 10.2337/diabetes.54.8.2430

7. Pretorius L, Thomson GJA, Adams RCM, et al. Platelet activity and hypercoagulation in type 2 diabetes. Cardiovasc Diabetol 2018; 17: 141. doi: 10.1186/s12933-018-0783-z

8. Randeria SN, Thomson GJA, Nell TA, et al. Inflammatory cytokines in type 2 diabetes mellitus as facilitators of hypercoagulation and abnormal clot formation. Cardiovasc Diabetol 2019; 18: 72. doi: 10.1186/s12933-019-0870-9

9. Peng X, Wang X, Fan $M$, et al. Plasma levels of von Willebrand factor in type 2 diabetes patients with and without cardiovascular diseases: A meta-analysis. Diabetes Metab Res Rev 2019: e3193. doi: 10.1002/dmrr.3193

10. Pomero F, Di Minno MN, Fenoglio L, et al. Is diabetes a hypercoagulable state? A critical appraisal. Acta Diabetol 2015; 52: 10071016. doi: 10.1007/s00592-015-0746-8

11. Sochett E, Noone D, Grattan M, et al. Relationship between serum inflammatory markers and vascular function in a cohort of adolescents with type 1 diabetes. Cytokine 2017; 99: 233-239. doi: 10.1016/j.cyto.2017.07.013

12. Pitocco D, Zaccardi F, Di Stasio E, et al. Role of asymmetric-dimethyl-L-arginine (ADMA) and nitrite/nitrate (NOx) in the pathogenesis of oxidative stress in female subjects with uncomplicated type 1 diabetes mellitus. Diabetes Res Clin Pract 2009; 86: 173-176. doi: 10.1016/j.diabres.2009.09.019

13. Babar GS, Zidan H, Widlansky ME, et al. Impaired endothelial function in preadolescent children with type 1 diabetes. Diabetes Care 2011; 34: 681-685. doi: 10.2337/dc10-2134

14. Lieuw-A-Fa ML, van Hinsbergh VW, Teerlink T, et al. Increased levels of N(epsilon)-(carboxymethyl)lysine and $\mathrm{N}$ (epsilon)-(carboxyethyl) lysine in type 1 diabetic patients with impaired renal function: correlation with markers of endothelial dysfunction. Nephrol Dial Transplant 2004; 19: 631-636. doi: 10.1093/ndt/gfg619

15. Mylona-Karayanni C, Gourgiotis D, Bossios A, Kamper EF. Oxidative stress and adhesion molecules in children with type 1 diabetes mellitus: a possible link. Pediatr Diabetes 2006; 7: 51-59. doi: 10.1111/j.1399-543X.2006.00147.x

16. Zahran AM, Mohamed IL, El Asheer OM, et al. Circulating Endothelial Cells, Circulating Endothelial Progenitor Cells, and Circulating Microparticles in Type 1 Diabetes Mellitus. Clin Appl Thromb Hemost 2019; 25: 1076029618825311. doi: 10.1177/1076029618825311

17. Fadini GP, Boscari F, Cappellari R, et al. Effects of Hypoglycemia on Circulating Stem and Progenitor Cells in Diabetic Patients. J Clin Endocrinol Metab 2018; 103: 1048-1055. doi: 10.1210/jc.201702187

18. Maiorino MI, Casciano O, Della Volpe E, et al. Reducing glucose variability with continuous subcutaneous insulin infusion increases endothelial progenitor cells in type 1 diabetes: an observational study. Endocrine 2016; 52: 244-252. doi: 10.1007/s12020-015-0686-7

19. Carrizzo A, Izzo C, Oliveti M, et al. The Main Determinants of Diabetes Mellitus Vascular Complications: Endothelial Dysfunction and Platelet Hyperaggregation. Int J Mol Sci 2018; 19: 2968. doi: 10.3390/ijms19102968

20. Abdel-Moneim A, Zanaty Ml, El-Sayed A, et al. Relation Between Oxidative Stress and Hematologic Abnormalities in Children With
Type 1 Diabetes. Can J Diabetes 2019; pii: S1499-2671(19)30592-1. doi: 10.1016/j.jcjd.2019.07.153

21. Venkatesh V, Kumar R, Varma DK, et al. Changes in platelet morphology indices in relation to duration of disease and glycemic control in children with type 1 diabetes mellitus. J Diabetes Complications 2018; 32: 833-838. doi: 10.1016/j.jdiacomp.2018.06.008

22. Zaccardi F, Rizzi A, Petrucci G. In vivo platelet activation and aspirin responsiveness in type 1 diabetes. Diabetes 2016; 65: 503-509. doi: 10.2337/db15-0936

23. Malachowska B, Tomasik B, Szadkowska A, et al. Altered platelets' morphological parameters in children with type 1 diabetes - a case-control study. BMC Endocr Disord 2015; 15: 17. doi: 10.1186/ s12902-015-0011-8

24. Vignini A, Moroni C, Nanetti L, et al. Alterations of platelet biochemical and functional properties in newly diagnosed type 1 diabetes: a role in cardiovascular risk? Diabetes Metab Res Rev 2011; 27: 277-285. doi: 10.1002/dmrr.1173

25. Spectre G, Stålesen R, Östenson CG, Hjemdahl P. Meal-induced platelet activation in diabetes mellitus type 1 or type 2 is related to postprandial insulin rather than glucose levels. Thromb Res 2016; 141: 93-97. doi: 10.1016/j.thromres.2016.03.009

26. Binay C, Bozkurt Turhan A, Simsek E, et al. Evaluation of Coagulation Profile in Children with Type 1 Diabetes Mellitus Using Rotational Thromboelastometry. Indian J Hematol Blood Transfus 2017; 33: 574-580. doi: 10.1007/s12288-017-0793-0

27. Kyrgios I, Maggana I, Giza S, et al. Suboptimal glycaemic control enhances the risk of impaired prothrombotic state in youths with type 1 diabetes mellitus. Diab Vasc Dis Res 2014; 11: 208-216. doi: 10.1177/1479164114528821

28. Adly AA, Elbarbary NS, Ismail EA, Hassan SR. Plasminogen activator inhibitor-1 (PAI-1) in children and adolescents with type 1 diabetes mellitus: relation to diabetic micro-vascular complications and carotid intima media thickness. J Diabetes Complications 2014; 28: 340-347. doi: 10.1016/j.jdiacomp.2014.01.011

29. Singh A, Boden G, Homko C, et al. Whole-blood tissue factor procoagulant activity is elevated in type 1 diabetes: effects of hyperglycemia and hyperinsulinemia. Diabetes Care 2012; 35: 13221327. doi: $10.2337 / \mathrm{dc} 11-2114$

30. Cimenti C, Schlagenhauf A, Leschnik B, et al. Only minor changes in thrombin generation of children and adolescents with type 1 diabetes mellitus - A case-control study. Thromb Res 2016; 148 : 45-49. doi: 10.1016/j.thromres.2016.10.016

31. Vitkovsky Y, Kuznik B, Solpov A, Magen E. Status of platelet-lymphocyte aggregation in circulating blood of patients with type 1 diabetes with and without diabetic nephropathy. Isr Med Assoc J 2008; 10: 691-694.

32. Yngen M, Östenson CG, Hu H, et al. Enhanced P-selectin expression and increased soluble CD40 Ligand in patients with Type 1 diabetes mellitus and microangiopathy: evidence for platelet hyperactivity and chronic inflammation. Diabetologia 2004; 47: 537540. doi: 10.1007/s00125-004-1352-4

33. Domingueti CP, Dusse LM, Fóscolo RB, et al. Von Willebrand Factor, ADAMTS13 and D-Dimer Are Correlated with Different Levels of Nephropathy in Type 1 Diabetes Mellitus. PLoS One 2015; 10 : e0132784. doi: 10.1371/journal.pone.0132784

34. Domingueti CP, Fuzatto JA, Fóscolo RB, et al. Association between Von Willebrand factor, disintegrin and metalloproteinase with 
thrombospondin type 1 motif member 13, d-Dimer and cystatin C levels with retinopathy in type 1 diabetes mellitus. Clin Chim Acta 2016; 459: 1-4. doi: 10.1016/j.cca.2016.05.011

35. Baker NL, Hunt KJ, Stevens DR, et al.; DCCT/EDIC Research Group. Association Between Inflammatory Markers and Progression to Kidney Dysfunction: Examining Different Assessment Windows in Patients With Type 1 Diabetes. Diabetes Care. 2018; 41 : 128-135. doi: 10.2337/dc17-0867

36. Astrup AS, Tarnow L, Pietraszek L, et al. Markers of endothelial dysfunction and inflammation in type 1 diabetic patients with or without diabetic nephropathy followed for 10 years: association with mortality and decline of glomerular filtration rate. Diabetes Care 2008; 31: 1170-1176. doi: 10.2337/dc07-1960

37. El Asrar MA, Adly AA, El Hadidy ES, Abdelwahab MA. D-dimer levels in type 1 and type 2 diabetic children and adolescents; Relation to microvascular complications and dyslipidemia "own data and review". Pediatr Endocrinol Rev 2012; 9: 657-668.

38. Verrotti A, Greco R, Basciani F, Morgese G, Chiarelli F. von Willebrand factor and its propeptide in children with diabetes. Relation between endothelial dysfunction and microalbuminuria. Pediatr Res 2003; 53: 382-386. doi: 10.1203/01.PDR.0000049509.65496.BF

39. Stančiaková L, Dobrotová M, Hollý P, et al. Trombofilné stavy. Vask Med 2017; 9: 54-58.

40. Dubský M, Jirkovská A, Pagáčová L, et al. Impact of Inherited Prothrombotic Disorders on the Long-Term Clinical Outcome of Percutaneous Transluminal Angioplasty in Patients with Diabetes. J Diabetes Res 2015; 2015: 369758. doi: 10.1155/2015/369758

41. Haller MJ, Valladares A, Rosenbloom AL. Arterial thrombosis resulting in amputation in a child with poorly controlled type 1 diabetes and heterozygous Factor $\mathrm{V}$ Leiden mutation. Pediatr Diabetes 2006; 7: 229-231. doi: 10.1111/j.1399-5448.2006.00181.x

42. Paniagua JA, Bahamondes R, Cano-Sánchez A, Velasco F. Unexpected papilledema in a young male with Type 1 diabetes. Clin Case Rep 2017; 5: 1333-1338. doi: 10.1002/ccr3.1067

43. Rosenbloom AL. Fatal cerebral infarctions in diabetic ketoacidosis in a child with previously unknown heterozygosity for factor $V$ Leiden deficiency. J Pediatr 2004; 145: 561-562. doi: 10.1016/j.jpeds.2004.05.044

44. Demirer AN, Alikasifoglu M, Tuncbilek E, et al. Factor V Leiden mutation and type 1 diabetes mellitus. Blood Coagul Fibrinolysis 2008; 19: 70-74. doi: 10.1097/MBC.0b013e3282f38c5f

45. Wang H, Madhusudhan T, He T, et al. Low but sustained coagulation activation ameliorates glucose-induced podocyte apoptosis: protective effect of factor $\mathrm{V}$ Leiden in diabetic nephropathy. Blood 2011; 117: 5231-5242. doi: 10.1182/blood-2010-10-314773

46. Sokol J, Chudej J, Hollý P, et al. Syndróm lepivých doštičiek. Vask Med 2016; 8: 60-62.

47. Solis-Jimenez F, Hinojosa-Heredia H, Garcia-Covarrubias L, et al. Sticky Platelet Syndrome: An Unrecognized Cause of Acute Thrombosis and Graft Loss. Case Rep Nephrol 2018: 3174897. doi: 10.1155/2018/3174897

48. Alsheekh AA, Puggioni A, Hingorani AP, et al. The sticky platelet syndrome during carotid endarterectomy. Ann Vasc Surg 2015; 29: 1317. doi: 10.1016/j.avsg.2015.02.022

49. Franco RF, Reitsma PH. Gene polymorphisms of the haemostatic system and the risk of arterial thrombotic disease. $\mathrm{Br} \mathrm{J}$ Haematol 2001; 115: 491-506. doi: 10.1046/j.1365-2141.2001.03175.x
50. Gong JY, Deng DT, Sun YH. Association of platelet glycoprotein receptor alpha2beta1 integrin and glycoprotein IIla gene polymorphisms with diabetic retinopathy: evidence from 3007 subjects. Curr Eye Res 2015; 40: 476-483. doi: 10.3109/02713683.2014.932386

51. Wang Y, Luk AO, Ma RC, et al. Predictive role of multilocus genetic polymorphisms in cardiovascular disease and inflammation -related genes on chronic kidney disease in Type 2 diabetes - an 8-year prospective cohort analysis of 1163 patients. Nephrol Dial Transplant 2012; 27: 190-196. doi: 10.1093/ndt/gfr343

52. Gao WF, Guo YB, Bai Y, et al. Association between PAl-1 4G/5G polymorphism and diabetic nephropathy: a meta-analysis in the Chinese population. Int Urol Nephrol 2016; 48: 1483-1489. doi: 10.1007/s11255-016-1333-9

53. Zhang T, Pang $\mathrm{C}$, Li N, et al. Plasminogen activator inhibitor-1 4G/5G polymorphism and retinopathy risk in type 2 diabetes: a meta-analysis. BMC Med 2013; 11: 1. doi: 10.1186/1741-7015-11-1

54. Siokas V, Dardiotis E, Sokolakis T, et al. Plasminogen Activator Inhibitor Type-1 Tag Single-Nucleotide Polymorphisms in Patients with Diabetes Mellitus Type 2 and Diabetic Retinopathy. Curr Eye Res 2017; 42: 1048-1053. doi: 10.1080/02713683.2016.1276197

55. Di Minno MND, Scalera A, Tufano A, et al. The association of adjusted Global AntiphosPholipid Syndrome Score (aGAPSS) with cardiovascular disease in subjects with antiphospholipid antibodies. Atherosclerosis 2018; 278: 60-65. doi: 10.1016/j.atherosclerosis.2018.09.010

56. Oliveira D, Ventura M, Melo M, et al. Addison's disease in antiphospholipid syndrome: a rare complication. Endocrinol Diabetes Metab Case Rep 2018; 2018: 18-0118. doi: 10.1530/EDM-18-0118.

57. Laadhar L, Zitouni M, Kallel-Sellami M, et al. Spectrum of autoantibodies in Tunisian adult type 1 diabetes mellitus. Ann N Y Acad Sci 2007; 1107: 356-362. doi: 10.1196/annals.1381.037

58. Gin H, Vergnot V, Diakou V, et al. Anti-phospholipid antibodies in diabetes mellitus. Clin Chem Lab Med 2002; 40: 604-608. doi: 10.1515/CCLM.2002.104

59. Abaci A, Bober E, Yeşilkaya E, et al. Prevalence of anticardiolipin antibodies in type 1 diabetes and autoimmune thyroiditis. Pol Arch Med Wewn 2010; 120: 71-75.

60. Galtier-Dereure F, Biron C, Vies M, et al. Vascular complications of diabetes mellitus: what role for phospholipid-binding antibodies? Lupus 1998; 7: 469-474. doi: 10.1191/096120398678920488

61. Lorini R, d'Annunzio G, Montecucco C, et al. Anticardiolipin antibodies in children and adolescents with insulin-dependent diabetes mellitus. Eur J Pediatr 1995; 154: 105-108. doi: 10.1007/BF01991910

62. Bećarević M, Čabarkapa V, Đerić M, Ignjatović S. Antiphospholipid Antibodies and Renal Impairment Parameters in Diabetic Nephropathy: Preliminary Data. Clin Appl Thromb Hemost 2017; 23: 379-383. doi: 10.1177/1076029616642512

63. Giusti C, Schiaffini R, Bosco D, et al. Lupus anticoagulant positivity in insulin dependent diabetic patients: an additional risk factor in the pathogenesis of diabetic retinopathy? $\mathrm{Br} J$ Ophthalmol 2000; 84: 531-533. doi: 10.1136/bjo.84.5.531

64. Cojocaru IM, Cojocaru M, Popescu AN, et al. Study of antiphospholipid antibodies in type 2 diabetes mellitus with and without diabetic retinopathy. Rom J Intern Med 2009; 47: 267-271. 